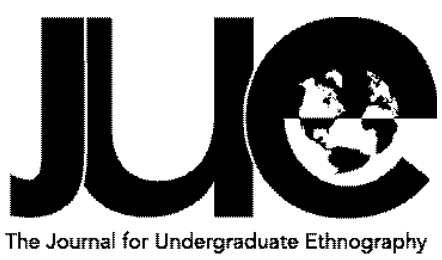

Volume 4 | Issue 1

\title{
Doing Gender on Stage: Karaoke and Gender Presentation
}

\section{Andrew Bisenius}

Portland State University, bisenius@pdx.edu

\begin{abstract}
his article investigates how karaoke participants "do gender". An ethnographic analysis of a karaoke bar in the Northwestern U.S. demonstrates how individuals routinely accomplish gender presentation. Previous research has indicated that karaoke's simulated character can provide a conduit for personal growth and interpersonal empathy. Each karaoke performance allows for several dimensions of gender presentation/identification (e.g. song choice, performance attitude, and clothing). In addition, audience participation and their reaction to the performer is observed to gauge the accountability of each performance. My findings indicate that men are more likely than are women to perform ironically, establishing that masculinity is reinforced by the efficaciousness of affecting the social environment through their use of humor. Additionally, the ironic male performance allows for the individual to avoid the risk of incompetence, a compromising component of masculinity that demands aptitude. In contrast, women are more likely than are men to perform mimetically, where an individual experiences a type of transcendence through the act of singing. Also, women performers tend to demonstrate the passive value of appearance in order to strengthen bonds with friends. Finally, I find that female performers tend to generate empathy from female audience members, reinforcing the traditional conception of femininity as nurturing.
\end{abstract}

Keywords: doing gender, karaoke, masculinity, femininity 


\section{INTRODUCTION}

As I walk into the dimly lit Sing Song Lounge, I am immediately greeted with loud music and the bartender's smiling face. It's another busy Friday night at this popular karaoke bar, full of groups seeking to sing the night away with their companions. I am without company and this absence of others is painfully obvious in such a highly social environment. Once I find a seat, I look over the songbook as a 20 -something year old woman is belting out Queen's "Somebody to Love". Most of the audience is in a state of awe as she slides down to her knees and sustains a note for about thirty seconds. I feel as if time has slowed during this sonic experience-the performer has put me in a hypnotic state. The singer is no longer just another karaoke participant; she has become Freddy Mercury incarnate. Once the performance is finished, the audience erupts in fits of applause and cheering while the red-faced performer smiles and waves out to the crowd. She returns to her seat and her friend group elatedly congratulates her.

The feeling of warmth from this experience dissolves my initial feelings of loneliness, and I feel compelled to participate despite my lack of vocal talent. I select a song from the book, fill out a song request slip, and return it to the emcee's booth. Since I cannot wow the crowd with my voice alone, I intend to entertain them with my humor instead. Karaoke allows a unique occasion to not just sing along with popular songs. It provides a medium for reaching complete strangers in creative ways. As the aforementioned illustration demonstrates, karaoke presents an opportunity for extending interpersonal interactions and sharing experiences. While this activity may initially appear to be innocent and rather mindless, karaoke is certainly rich in sociological content. When considering the gender of each participant, patterns indubitably emerge in the variation of performance styles. From this observation the question ariseshow exactly do karaoke participants "do gender"?

\section{LITERATURE REVIEW}

West and Zimmerman's “Doing Gender” (1987) attempts to conceptualize gender as a distinct category, independent from biological sex. In opposition to the essential natures suggested by the biological model, the authors claim gender is a product of social situations and a rationale for various social arrangements, providing a means of legitimating one of the most fundamental divisions of society (West and Zimmerman $1987,126)$. Gender is therefore an activity of managing behavior within a normative social structure, whereby an individual must exhibit certain conduct that is viewed as appropriate for their respective sex category. A web of methods are used by individuals to routinely accomplish gender, culminating in the construction of a gendered social reality. This conception differs significantly from the popular notion of gender rolesan idea that assumes two distinct categories (masculinity and femininity) of behavior can be easily applied and recognized in the multiplicities of interactional situations. In contrast, doing gender consists of managing such interactional occasions so that, whatever the particulars, the result is either genderappropriate or -inappropriate, that is, accountable (West and Zimmerman 1987, 135). Accountability is a crucial component of doing gender. Being accountable entails not only presenting an account of one's gender but to apply the sex categories to others in order to assess an individual's success in meeting the normative expectations. Accountability therefore entails that doing gender is to engage in conduct at the risk of gender assessment (West and Zimmerman 1987, 136).

As a theoretical framework, doing gender expands the scope of sociological investigation into the continuous construction and maintenance of the binary gender categories of masculinity and femininity. As the authors note, many situations are not openly sex categorized to begin with, nor is what transpires within them obviously gender relevant-yet any social encounter can be pressed into service in the interests of doing gender (West and Zimmerman 1987, 138). This implies the doing of gender can be observed in any social space. Thus, I use the concept of doing gender in order to investigate how karaoke participants do gender at a popular karaoke bar in the Northwestern United States.

Previous empirical research of karaoke further demonstrates its sociological significance. In "Once More, With Irony: Karaoke and Social Class” Rob Drew claims karaoke’s 
mimetic character can provide a conduit for personal growth and interpersonal empathy (Drew 2005, 371). This claim entails that karaoke is fundamentally an exercise of expression and self-transformation. The author argues social class determines how one views his claim, with lower- and working-class individuals finding more affinity to its transformative character, while middle-class urbanites develop an alternative, ironic understanding of karaoke. Therefore, the opposing performance styles, mimetic and ironic, are to be understood as enactments of social class.

A mimetic performance is at the heart of karaoke. Drew makes this point salient by noting, "Karaoke performance is an essentially mimetic practice...its template is not a written set of lyrics, nor even a song composition, but a full-blown, prior performance: a popular recording" (Drew 2005, 378). Initially, this mimetic quality would appear limiting but in fact it allows for a wide range of expression, from song choice to the minor details of a performance. Karaoke fosters an environment where individuals can experiment with different popular genres that may not appear to correspond with their identity of perceived tastes. The audience serves a mirroring function that transmits approval or distain for the attempt to embody an identity that is unfamiliar yet appealing to the performer. The performer's attempt at self-transformation is thus a crucial component of the mimetic performance and the act of karaoke itself.

An ironic performer stands in opposition to the mimetic call of karaoke. They reject the limited range of expression that demands submission to the original popular song in order for a successful performance. The ironic performance category is determined primarily by its distanced mode of performance expressing class distinction and exclusion through cultural forms and practices (Drew 2005, 374). Within the middle-class karaoke scene, karaoke became accepted based on the mutual agreement that it is not to be taken seriously. Popular indicators for signifying this lack of sincerity include singing in exaggerated and inappropriate styles, adopting comic voices, or frequent laughter throughout a performance (Drew 2005, 376). Humor and subsequent laughter can be interpreted as a vehicle to successfully distance themselves from the performance practice in itself. Thus, laughter from the performer and audience demonstrates participation in the collective joke.

By investigating how karaoke participants do gender at a popular karaoke bar in the Northwestern US, my research draws heavily from Drew-especially his categorization of mimetic and ironic performance styles. I argue that men are more likely to adopt an ironic performance style because of a fear of incompetence and refusal to submit to the lyrics. In this refusal to follow the lyrical structure of the song, men demonstrate their gender ideal of "efficaciousness" (West and Zimmerman 1987, 141). By deploying tactics of humor and detachment, men are able to affect the social environment to produce laughter. In contrast, women tend to sing in a mimetic style, submitting to the scripted lyrics while simultaneously expressing self-transcendence. I argue that women performers tend to demonstrate the passive value of "appearance" in order to strengthen bonds with friends. Also, women who take an active approach to singing engage in a process of self-transformation and share the emotional content of this self-expression with the audience. I then shift my focus from the performer to the audience. I find that female performers tend to generate empathy from female audience members, reinforcing the traditional conception of femininity as nurturing.

\section{METHODS}

This article is the result of approximately 20 hours of ethnographic research conducted over eight weeks in an urban karaoke bar located in the Northwestern US. By adopting the ethnographic methodology, a researcher can access the experience of the karaoke participant and audience. It has been said that the role of the ethnographer is to reveal the multiple truths apparent in others' lives instead of focusing on "the truth" (Emerson 2011). Due to the nightlife nature of most karaoke bars, I attended the site during the night ( $9 \mathrm{pm}-1 \mathrm{am})$. I visited the site eight times with a duration that varied from one to four hours. I collected data by recording detailed jottings on my mobile device. Since I would typically not return home until late at night, I wrote field notes based on my jottings the day after observation. I always attempted to write as soon as possible the following day and never allowed more than 24 hours between visiting the site and writing field notes. By allowing a significant passage of time between these two events, I acknowledge the potential for less valid data. Nevertheless, my methodology is sanctioned for research being conducted in late hours to avoid careless mistakes due to fatigue (Emerson 2011, 49). 
The name of the site has been changed in order to maintain confidentiality and will be referred to as Sing Song Lounge. Sing Song is a rather large, one-story building with two distinct sections. The first section resembles a typical bar including dim lighting, a large wooden bar with countless bottles of alcohol displayed on shelves, booths, numerous televisions, pool tables, video lottery machines, neon signage of beer companies and a photo booth. The walls are covered with $4 \times 6$ photographs of smiling faces taken at the site in the past. The two sections are separated by a rather narrow hallway. The second section is designated for karaoke. It is more dimly lit than the first section with small neon lights on the ceiling emanating a bluish glow and has a rectangular shape. There is ample seating for at least 80 people, with numerous tables pushed together, along with bar-style seating along the northern wall. One of the two bar-seating areas is across the cocktail waitress' station, and is where I normally sat for observation due to its more central location. The southern wall is lined with windows, advertising the karaoke to those who pass by on the busy street. At the west end of the room, the karaoke jockey or "KJ" sits behind a booth that is between two large television screens, which display the scripted lyrics. The "stage" is marked by the black and white checkered floor along with a disco ball dangling from the ceiling and is directly in front of the $\mathrm{KJ}$ booth. Music can be heard from any point in the site and even outside at times. There is commonly a lot of traffic between the two sections and so the number of audience members can vary dramatically per performance.

Given the demographics of this particular part of the city, patrons were overwhelmingly white, around the age of thirty and the distribution of men and women was generally equal. Most of the patrons would be thoroughly intoxicated by the time I ended my observations. The site was chosen based on its reputation and popularity as a bar that offered karaoke every night of the week. While I did observe a small group of regulars, generally the participants were in groups (typically composed of four or more individuals) that I would only observe for one night. Additionally, I chose to exclude the Sing Song's employees to narrow my observations to strictly performances. I spoke most often with employees, and they offered me valuable information about the site, such as the busiest nights to attend and Sing Song's history. I did not conceal my purpose as a researcher, and my motives for patronizing the site were never brought into question.
After my second visit I decided to perform. While I had prior karaoke experience, the thought of performing intimidated me because I attended the site alone so I had no guaranteed support. The decision to perform ultimately was caused by my feelings of being an outsider. I concluded that if I sang, then I would generate some potential for social interaction with the strangers around me along with eliminating the potential for making others uncomfortable with my presence as an observer. Additionally, performing provided rich insight into the experience of the individual on stage. The emotional and physical response that comes with the vulnerability of performing gave me a heightened awareness of the performances, since I also had to select a performance style. I did not consciously choose a performance style, but I would have coded myself as an ironic performer. I most frequently performed Salt-N-Pepa's "Push It" due to the convenience of familiarity and comfort with its vocal simplicity. This personal decision allowed me to dismiss concerns that a performance must be based in some deliberation but most likely was a result of individuals reacting to a heightened sensitivity to interpersonal communication. While my performances served a function of allotting me important insight into the experience of the performer, it was difficult to observe the audiences response and these findings will not be included.

\section{RESULTS}

Ultimately, karaoke performances generated gendered meanings. First, I look at how these gendered performance styles bifurcate into two primary categories-ironic and mimetic. I find men were more likely than women to perform ironically; women were more likely than men to perform mimetically. Second, I look at the response from the audience members. I find women performers tended to generate empathy from other women audience members, resulting in women audience members joining the women performers on stage to show support.

\section{Masculinity in Ironic Performance}

The ironic performance style is characterized by its overt detachment from singing, thereby negating the risk of failure. One of the most frequent signifiers for demonstrating detachment was the deployment of humor. Humor is typically presented explicitly, through facial expressions, uses of the stage space, vocal tone, song choice, and diverting from the original lyrics 
with crude substitutions. In addition, this style tended to have a strong effect on the overall environment. This observation aligns with West and Zimmerman's claim that masculinity strives for an ideal of "efficaciousness"-a notion that one can affect the environment through an exercise of physical strength or appropriate skills (West and Zimmerman 1987, 141). In my observations, males overwhelmingly utilized this performance style. The ironic style can be aligned with presentations of masculinity in two primary ways.

First, the ironic style avoids the risk of incompetency. Demonstrating competency is a crucial characteristic to the construction of a masculine identity (Pascoe 2005, 337). By engaging in an ironic performance the male performer does not have to worry about impressing the crowd with their vocal skill, nor do they express any emotional content. By limiting the danger of judgment by the audience, the odds of being seen as competent increase significantly. The detached mode of performance allows for any deflection of potential criticism because it communicates that the performer simply does not care about traditional karaoke. With an ironic style, all that can be expressed is humor. Thus, it is the role of the ironic performer to express these sentiments as well as demand the audience to pay attention to them by loudly performing.

An instance of this ironic performance was when a white male in his 20s approached the stage with a wide grin across his face. On first glance, his appearance seemed to be crafted for his karaoke performance. His long, frizzy blonde hair is parted down the middle and was adorned with a purple headband. He wore a white Hawaiian styled shirt with orange and yellow parrots perched upon some tropical branches along with some faded, tightly fitting blue jeans. Performing "Simply Irresistible" by Robert Palmer, he began by jumping up and down energetically. He yelled the lyrics into the microphone, along with some occasional laughter. About halfway through the song he moved his hips violently, simulating a sexual act. The laughter of the crowd began to overpower the audio as he continued to move around fiercely, yelling along with the chorus louder than before. During the musical break he let out small fits of laughter into the microphone as he continued his air-humping act. Once the song ended, the red-faced performer was sweating profusely as he returned to his table of friends and was greeted with numerous high-fives. He and his group of friends were all laughing hys- terically. He sat down on a stool and proceeds to kiss one of the women in the group. This performance served as an ideal type of the ironic performance. As an appropriate demonstration of masculinity as hyper-sexual, the performer humorously alluded to sexual acts. His use of yelling, comedic attire, song choice, and stage presence all illustrate his use of skills in order to affect the physical and social environment. The amount of effort put forth by the performer to provide such a comedic performance demonstrates how strongly he desired approval from the audience as well as commanding the audience's attention.

While men used the ironic style most often, there were some men that demonstrated masculinity in a mimetic style. Typically, these men were either older than the average patron (40+ years old) or they were with a female significant other. I can only assume that the differences of performance styles between generations reflect the shift in attitudes towards karaoke over time (Drew 2005). For example, a stocky white male in his 40s with a grey beard wearing a leather bandanna along with a leather vest over a leather jacket, a large oval belt buckle and blue jeans sang a country tune I could not identify. This very masculine, biker sort of man met all the criteria for a mimetic performance (e.g. eyes closed, seriousness, adhering to lyrics etc). While he was not a very strong singer, his genuine performance demonstrated prior research that karaoke is classed (Drew 2005). This man's clothing signifies allegiance to the working-class. The difference in attitude would therefore be due to the possibility that this individual has been performing karaoke before the creation of the ironic style in the 1990s.

Some men also utilized the mimetic performance when they were with a female significant other. For instance, a white male in his 30s with blonde spiked hair and sideburns, wearing a pink hoodie over a grey shirt with blue jeans and brown leather boots sang Joe Cocker's "You Are So Beautiful". He made a significant amount of eye contact with his female partner in the audience, who had a bouquet of flowers laid across her lap. He closed his eyes during the more vocally demanding parts and would flash a smile to her during the musical breaks. When the same performer sang another song, whenever the romantic lyrics were about a "lover" he would point at his female friend and make strong, prolonged eye contact with her. This mimetic performance serves a function of expressing sentiments of love to his female partner. Prior research has investigated the emergence of the "sensitive" 
man, which expresses love and romance. These characteristics are valued more highly in men because they are not seen to be a part of their essential masculine nature, thus presenting a potential threat to their masculinity. It has been argued that this apparent alternative masculinity is simply another method of demonstrating their masculine identity because it signifies their desirability to women and active heterosexuality (Weber 2012, 917). Therefore, these performances do not discredit the claims that an ironic style is masculine, but rather strengthen the argument that karaoke is a gendered activity.

\section{Femininity in Mimetic Performance}

The mimetic performance embodies the spirit of karaoke. Additionally, a mimetic performance is vulnerable to critique, where one's performance can be evaluated as successful or not. The physical attributes can include a serious attitude, closing of the eyes while singing, adherence to the lyrics, microphone techniques, and swaying/dancing to the rhythm. I find that femininity is expressed in the mimetic performance because of its submission to the scripted lyrics and expressing a transcendence of self that the performer intends to share with the audience. Depending on the performer, a mimetic performance can range from a quiet performance where the performer appears nervous and timid to a performance that reenacts pop star qualities. Thus, the feminine mimetic performance generally manifested itself in two subcategories, the Shy Girl and the Diva.

The Shy Girl was the most frequent performance from women. It usually was accompanied with a duet, which will be discussed later. Typically, this performance would be defined by a performer staring at the screen, standing still, and quietly singing. This passive style of performance supports the idea that females are to value "appearance" whereby women are to manage themselves as ornamental objects (West and Zimmerman 1987, 141). For instance, a white female in her 20s sang Queen's "You're My Best Friend" with a soft voice that was barely audible over the backing track. She stood still with her eyes fixed on the screen. There were conversations that were louder than the performance. Then a female friend of hers came to her rescue, grabbed another microphone and sang the rest of the song alongside her. As is characteristic of the shy girl performance, it would typically be steeped in anxious energy. The performance began passively and quiet, illustrating the importance of appear- ance over active interaction. By engaging in the mimetic performance, they attempt to reach a point of self-expression, but their tendency toward passivity hindered their ability to do so. After observing enough of these performances, I noticed the female performers were singing exclusively for their friends. They were searching for connections with their other female friends, and these friends would typically approach the stage and join in on the performance. So what the Shy Girls desired was ultimately bonding with their female friends. Therefore, self-transcendence was less about the vocal performance and more about deepening interpersonal connections.

To be a Diva, the performer needed to demonstrate mastery in her performance. This would include all of the criteria listed above, along with a certain energy that transforms perceptions of the person. For instance, a heavier white female in her 30s with long blonde hair and a red bandana was wearing a grey low-cut shirt, blue jeans, and red converse shoes approached the stage. As she began her rendition of Queen's "Somebody To Love" I could immediately tell she was a trained singer as she belted out a flawless performance of the rather difficult song. There was never a moment of dissonance, even when she would sing an octave higher than the original vocals. She closed her eyes frequently demonstrating her mastery over the lyrics. Using microphone techniques such as pulling the microphone away from her mouth as her voice increased in volume, she was able to accomplish a professional quality performance. Swaying to the music, she would also pat her thigh with her free hand to the rhythm. As the song progressed so did the redness in her face-she put all her effort into the performance. At the climax of the original song, she fell to her knees, leaning her head back as she sustained a note for well over five seconds and remained on the ground for the remainder of the song. This performance demonstrates the transformative magic behind karaoke. Before the performance, it would be hard to imagine the performer as being someone with a stunning voice. She not only submitted to the lyrics, she completely embodied the song. It is precisely this embodiment that allows for a person to share with others the kind of self-discovery that can happen during a performance. By disregarding the call for passivity, they actively engage with the song to generate a connection with the audience.

Audience Participation 
Without an audience, karaoke would be a rather meaningless activity. Through a variety of tactics, the performers strive to connect with the audience and obtain approval for their performance. The audience functions as a regulatory mechanism, displaying approval in the form of applause and disapproval through lack of applause and indifference. Doing gender requires such a regulatory process, where individuals monitor their own and other's behavior in regard to its gendered connotation (West and Zimmerman 1987, 142). Applause during and after a performance generally varied on the performances and no significant themes were found. In my observations I found women performers tended to generate empathy from other women audience members, resulting in women audience members joining the women performers on stage to show support. Support could take the form of a premeditated duet, spontaneous duet, or simply joining the performer on stage and dancing. I interpret this finding to signify that women utilized self-regulation not only to give encouragement to the performer, but also to demonstrate their nurturing nature-a hallmark trait of femininity.

Typically, the Shy Girl performances received the most support from audience members. Rarely would a Shy Girl complete a song alone. I never observed a duet of two Divas. The most common form of support appeared as a premeditated duet, where two or more performers would sing a song cooperatively. By and large, duets were utilized by female performers. For example, two white females in their 20s sang a song that was unfamiliar to me. They decided to only use one microphone even though there was an additional one available, and this caused them to have their faces close to each other. As they sang, they made direct eye contact with one another and were holding hands. Their voices were rather quiet and sometimes they would giggle. This performance demonstrates how two females cooperatively present themselves as passive, ornamental objects who support each other through such a vulnerable situation.

A spontaneous duet occurred when a single performer would begin the song and then someone would join in midsong. Typically, this would occur when a female performer was struggling through a song, was too quiet, or had a rather terrified look on her face. Usually the late addition would fall closer to the Diva category, and inject the performance with an active enthusiasm. Using the previous example from the definition of the Shy Girl, the timid performer began her performance heavily struggling, with a voice that was hardly audible. A white female in her 30s that was larger than the performer grabbed the other microphone and began singing loudly. She had black and bleach blonde hair that was pulled back into a ponytail, wearing a sheer black lace dress and had a few colorful tattoos on each arm, along with black boots that went up to her knees. As she put her arm over the shoulder of the initial performer, she belted out the chorus, injecting energy into the performance. The previously timid performer gained confidence from this display of support and enthusiastically completed the song along with her friend. This performance demonstrates the general importance of cooperation for the Shy Girl, as she was instantly relieved of the anxious energy once her friend joined her. Due to the passive nature of the Shy Girl performance, she needed a livelier partner to encourage an active style.

The most popular form of audience participation was when audience members would join a performer on stage but would not sing. This would usually be in the form of dancing, and overwhelmingly this form of support was shown by women in the audience. The gender of the performer was less significant than the duets, but still female performers received the most support. If any men engaged in this activity, it was due to their relationship with a woman already on stage or an attempt to signify humor. Thus, this final form of support further solidifies the claim that women in the audience are engaging in a self-regulatory activity, demonstrating their nurturing natures and tendency toward cooperative interaction. For instance, a white female in her 30s with short blonde hair, wearing a loosely fitting black blouse, a medallion necklace that hangs to her abdomen, a black skirt, black leggings and black boots sang Liza Minnelli's “Don't Tell Mama" timidly. Two white females approached the stage and began dancing by slowly swaying. As the song progressed the dancers began moving their arms in the air slowly and moving their hips. This gave the performer more confidence as the volume of her voice increased and she also began to move around with her supportive crew.

Another example involves a black male in his 30s performing "Under the Sea" from the film "The Little Mermaid". He wore thin rimmed glasses, a green sweater, a gold watch, faded blue jeans and black boots. His performance was very ironic, given the silly nature of the song, and he was smiling and laughing throughout. Four white females in their 20s approached the 
stage and started to dance around him. Everyone on stage was laughing, as well as everyone in the audience. At the end of the performance, one of the females shook his hand as the crowd cheered loudly. So while there were differences in gender, the female audience members maintained their passive form of dancing as ornamental objects, while simultaneously actively engaging in a cooperative activity of song and dance.

\section{DISCUSSION}

Ultimately, this research suggests that males and females do gender according to their perceived biological sex at the Sing Song Lounge. Men utilize the ironic performance style in order to present their masculinity, which involves a fear of incompetence and demonstration of efficaciousness. Women performed mimetically to demonstrate their femininity, presenting either a passive performance that is quiet and appearance based, or an active performance that attempts to express feelings of self-transformation with the audience. Additionally, women performers were much more likely to generate empathy from female audience members, resulting in displays of cooperative and nurturing natures. Karaoke provides a medium for a hyperperformance of gender, where an individual is given the opportunity to select a song they feel represents who they are. Moreover, they can choose a performance style that will determine the possible outcomes for how the performance will be evaluated. It is clear that generally, men and women chose their respective performance styles in order to maintain accountability for their gendered performance.

These findings of gender performances rely heavily upon 
the context of the karaoke bar, which provides a space for individuals to experiment with different identities. It would be insufficient to claim that these gendered performances can be transferable to other social interactions. Also, the findings of this article are not intended to be generalizable to all karaoke bars. The study of this karaoke bar exposed the gendered meanings behind such a casual activity. By noting some recurring themes, this investigation provided valuable insight into how gender performance permeates even the most insignificant events. The dichotomous nature of an essentialized gender model manifested itself within the two opposing performance styles. These similarities between the two types of categorization demonstrate how idealized notions of masculinity and femininity function as mutually exclusive categories. While there were mimetic males and ironic females, there was no one that mixed the two styles, thus respecting the borders of these categories. In the end, the findings of this article indicate that gender does not arise out of the contingency of individuals but is the product of social interaction and accomplishment.

When thinking of possibilities for future ethnographic research, it would be interesting to investigate how gender is done differently in karaoke bars that are more racially diverse or in the more working-class karaoke bars. The racial and social class uniformity of Sing Song lounge undoubtedly affected my observations of gendered performances. Also, studying karaoke nights in gay bars could yield interesting results due to the lack of heteronormativity operating within a site. Extending outside of ethnographic methodology, it would been beneficial to gain insights of the attitudes of karaoke participants through the use of interviews. This could generate a more nuanced understanding of what performance styles actually mean to the performers as individuals. 


\section{REFERENCES}

Drew, Rob. 2005. "Once More, With Irony: Karaoke and Social Class." Leisure Studies 24(4): 371-383.

Emerson, Robert M., Rachel I. Fretz, and Linda L. Shaw. 2011. Writing Ethnographic Fieldnotes. University of Chicago Press.

Pascoe, C.J. 2005. "Dude, You're a Fag': Adolescent Masculinity and the Fag Discourse." Sexualities 8(3): $329-436$.

Weber, Jennifer B. 2012. "Becoming Teen Fathers: Stories of Teen Pregnancy, Responsibility, and Masculinity." Gender \& Society 26(6): 900-921.

West, Candace and Don H. Zimmerman. 1987. "Doing Gender." Gender and Society 1(2):125-151.

This work is licensed under a Creative Commons AttributionNonCommercial-

NoDerivs 3.0

Unported License. 